\title{
Reforma agraria y práctica política en el contexto del desarrollo y la modernización, Argentina, 1955-1975
}

\author{
Agrarian Reform and Political Practice \\ in the Context of Development \\ and Modernization, Argentina, 1955-1975
}

\author{
Silvia B. Lázzaro* \\ Consejo Nacional de Investigaciones Científicas y Técnicas, \\ Universidad Nacional de La Plata, Buenos Aires, Argentina, \\ slazzaro@isis.unlp.edu.ar
}

\begin{abstract}
Resumen. El propósito es el estudio de los proyectos de reforma agraria en Argentina durante el periodo de la expansión capitalista de posguerra y frente al intento de redefinición del proceso de acumulación con el retorno del peronismo, sus condicionantes internacionales y locales, y sus resultados. Nuestra hipótesis sostiene que todos los intentos de la reforma agraria, de los diferentes regímenes políticos del periodo, tuvieron como fin primordial garantizar el predominio de la concentración de la tierra, alejados de toda pretensión de índole redistribucionista. En la estrategia metodológica tiene preeminencia el análisis cualitativo. Ello con base en la consulta, el análisis y la crítica de la bibliografía de la época y la actual, fuentes oficiales, publicaciones periódicas sobre temas rurales, y de las corporaciones agrarias, en el marco de un cometido central que apunta al conocimiento de procesos escasamente abordados desde la historia de manera integral.
\end{abstract}

Palabras clave: reforma agraria; política agraria; modernización; desarrollo rural; región pampeana.

Abstract. The purpose is the study of the agrarian reform projects in Argentina during the period of the post-war capitalist expansion and the attempt to redefine the process of accumulation with the return of peronism; their international and local conditions; and their results. Our hypothesis argues that all the attempts of the agrarian reform, present in the agenda of the different political regimes of the period, had as primary

* Consejo Nacional de Investigaciones Científicas y Técnicas (CONICET); Facultad de Humanidades y Ciencias de la Educación de la Universidad Nacional de La Plata. Una versión previa de este texto fue presentada como ponencia en las XXV Jornadas de Historia Económica de la Asociación Argentina de Historia Económica, realizadas en la Universidad de Salta, septiembre de 2016.

Am. Lat. Hist. Econ., sep.-dic., 2017, pp. 193-223 | DOI: 10.18232/alhe.v24i3.834 
aim to guarantee the predominance of the concentration of the land, away from any pretension of redistribution. In the methodological strategy, the qualitative analysis has preeminence. This is based on the consultation, analysis and criticism of current and current bibliography, official sources, periodicals on rural issues, and agrarian corporations. All this in the context of a central task that aims to the knowledge of processes that have been scarcely approached from History in an integral way.

Key words: agrarian reform; agricultural policy; modernization; rural development; Pampean region.

JEL: N86; N96; Q18.

Fecha de recepción: 2 de diciembre de 2016. Fecha de aceptación: 28 de febrero de 2017.

\section{INTRODUCCIÓN}

$\mathrm{D}$ esde mediados del siglo XX el tema de la reforma agraria se fue erigiendo en una de las cuestiones de política pública más discutida en América Latina y en el fundamento de importantes debates políticos. En general el punto de partida fue generado por el estancamiento económico del sector agrario y por la injusta distribución de la propiedad, el ingreso, el poder y las oportunidades detentadas por las elites rurales.

La reforma agraria es un proceso de transformación socioeconómico que supone cambios radicales en las estructuras de propiedad, tenencia y acceso a los medios de producción. Y supone un grado de exacción de los sectores terratenientes en tanto debilita las bases de su poder económico y político (Oszlak, 2016).

A comienzos de la década de 1950, la Organización de las Naciones Unidas para la Alimentación y la Agricultura ${ }^{1}$ realizó un informe sobre los regímenes de propiedad rural y su relación con los bajos niveles de desarrollo. La existencia de latifundios de cultivo extensivo -característica de la estructura agraria de América Latina- era lo que determinaba la baja producción de alimentos y las deficientes condiciones sociales de la población rural: "En alguno de los países más importantes de América del Sur abunda la tierra cultivada y la tierra cultivable en relación con la población, pero la concentración de la propiedad en latifundios reduce a una gran parte de la población rural, a la condición de 'peones' cuyo nivel de vida es muy bajo, o de pequeños agricultores con condiciones de arrenda-

${ }^{1}$ Organización de las Naciones Unidas para la Alimentación y la Agricultura (1951). Reforma agraria. Defectos de la estructura agraria que impiden el desarrollo económico, citado en Jordán (1989). 
miento muy precarias” (Jordán, 1989, pp. 12-14). Dicho informe proponía distintas medidas susceptibles de adoptar según los casos: sustitución del sistema de arrendamientos por el de propiedad, creación de cooperativas de crédito y de comercialización, servicios de capacitación y asistencia tecnológica y desarrollo de las industrias rurales.

En efecto, en América Latina, frente al generalizado fenómeno de concentración de la tierra, se fueron generando intentos de redistribución de la misma en diferentes países, condicionados por presiones de los sectores menos protegidos, por intereses políticos, o por un marco internacional que buscaba el cambio de las estructuras agrarias (procesos de México, Bolivia, Guatemala, Cuba, Venezuela, con diferentes propósitos y resultados en cada caso). Pero en general los objetivos eran mejorar las condiciones de vida de los campesinos, permitirles la posibilidad de la demanda interna en el mercado para la industrialización, atemperar situaciones sociales conflictivas y evitar la reiteración de procesos revolucionarios al estilo cubano.

En la década de 1960 los intentos de reforma agraria estructural se debilitaron dando paso a la denominada revolución verde -modelo de agricultura moderna que Estados Unidos transfiere a los países en vías de desarrollo y que incluye el uso de un paquete tecnológico específico integrado por semillas híbridas y mejoradas, pesticidas, fertilizantes y la mecanización de labores, favoreciendo la aceleración de los tiempos productivos y la homogenización de la producción- como prototipo mundial del desarrollo capitalista en el agro con el predominio de nuevas tecnologías del desarrollo rural integrado (Gras y Hernández, 2016, p. 35). Concebimos como reforma agraria estructural a aquella que integra un proceso nacional y global de transformaciones revolucionarias liderado por un nuevo elenco de fuerzas sociales que toman la iniciativa de la conducción política y fundamentada en la modificación radical de las relaciones de poder y de las normas institucionales que las articulan y sustentan. Antonio García (1973, pp. 27 y 178-183) distingue tres grandes modelos políticos de la reforma agraria en América Latina: el modelo de reforma agraria estructural, comprendida dentro de un proyecto nacional-revolucionario (México, Bolivia, Perú) o articulado con un esquema socialista de desarrollo (Cuba); el modelo de reforma agraria convencional, que funciona como una operación negociada entre antiguas y nuevas fuerzas sociales, implantando políticas de modernización tecnológica y social, mejorando normas de funcionamiento de la estructura agraria pero sin transformaciones de fondo; y el modelo de reforma agraria marginal, diseñado por las propias clases dominantes que se orienta hacia la preservación de la estructura latifundista, sobre la base de políticas de modernización agrícola, de colonización de tierras fiscales y de parcelación de latifundios marginales. A nuestro criterio, las iniciativas generadas en Argentina tuvieron claramente los perfiles de una reforma agraria marginal. 
Durante los años setenta el tema de la redistribución de la tierra se fue desvaneciendo, a lo que no fue ajena la multiplicación de regímenes autoritarios con fuertes perfiles de ideas neoliberales que pusieron énfasis en procesos tales como la modernización capitalista, el papel del mercado como asignador de recursos, y la necesidad de producción agraria para enfrentar el endeudamiento externo (Chonchol, 2003, p. 210).

En efecto, ya en los años cincuenta la situación socioeconómica y política de varios países latinoamericanos tendió a cambiar y se fue instalando la convicción de que era inevitable la necesidad de enfrentar el problema agrario mediante una transformación estructural (en la doble perspectiva de la justicia redistributiva y del aumento de la productividad) con una connotación cada vez más integral. Ello explica que la reforma agraria adquiriera su significación como instrumento de desarrollo socioeconómico en todos los procesos que se realizaron a partir de la década de 1960 (Ortega, 1990, pp. 104-105).

Así, la reforma agraria se constituyó en un mecanismo jurídico de cambio social que se institucionalizó desde el Estado, y por ende la indicación respecto a qué se reformaba, cómo y para qué dependió en cada caso del proyecto político respectivo y de las concertaciones entre los diferentes grupos de interés.

La difusión que tuvo la reforma como proceso susceptible de modificar la estructura agraria latinoamericana en las décadas mencionadas, no impactó en Argentina; fundamentalmente porque en la región más dinámica -la pampeana- no había una estructura agraria muy polarizada, a causa de la carencia de una presión campesina por la tierra, y por la ausencia de programas de reforma agraria en los partidos políticos más importantes. En países como Argentina, de avanzada urbanización y relativa industrialización, la presión más intensa desde el punto de vista económico y político, no era la "presión campesina" sobre la tierra, sino la "presión nacional", originada en la confluencia de factores sociales como el crecimiento demográfico, la acelerada urbanización, la concentración poblacional en las grandes ciudades, la demanda industrial de materias primas, y la aspiración de las clases trabajadoras a un más alto nivel de vida. En la medida en que esa presión se intensificara, "se podría diseñar una reforma agraria de afuera hacia adentro", o sea, de las exigencias del desarrollo global hacia la estructura agraria (García, 1973, p. 48).

Incidieron procesos externos, fundamentalmente la política estadunidense manifestada en la alianza para el progreso que legitimó la reforma agraria como una forma "no revolucionaria" de cambio social, a través de organismos tales como la Comisión Económica para América Latina (CEPAL) y la Comisión Interamericana de Desarrollo Agrícola (CIDA). En efecto, en el marco de este concierto internacional, los gobiernos de Amé- 
rica Latina se comprometieron a realizar cambios estructurales en contrapartida de la ayuda económica por parte de Estados Unidos, con escasas derivaciones en tanto se limitaron a aprobar leyes de reforma agraria sin acompañarlas de acciones consecuentes, y con un resultado limitado: la reforma agraria deja de ser considerada como un elemento exclusivo de la subversión comunista contra las democracias de América Latina (Chonchol, 2003, p. 209).

En el marco del debate sobre el subdesarrollo latinoamericano, la insistencia en la necesidad de la reforma agraria ha sido recurrente. Especialmente durante la década de 1960 y 1970, tras el estallido revolucionario en Cuba y con la experiencia de las reformas mexicana y boliviana, es cuando los teóricos del desarrollo hacen emerger la alternativa redistributiva como elemento esencial que debiera permitir incrementar los niveles de renta y consumo de la población rural, fomentar el mercado interno, convirtiéndose así en un gran acicate para la industrialización y fundamentalmente conjurar el peligro que por entonces suponía el ejemplo cubano para la hegemonía de Estados Unidos en el continente.

El proceso cubano fue el detonante que condujo a la administración estadunidense a apostar -vía Alianza para el Progreso- por un tipo de reformas moderadas. La Alianza se comprometió, en el seno de la Conferencia de Estados Americanos de Punta del Este, a fomentar, de acuerdo con las características de cada país, programas de reforma cuyo objetivo final sería la consecución de un sistema de tenencia equitativo y socialmente más justo y estable. Es significativo que haya sido en la Conferencia de Punta del Este donde se empleó la expresión reforma integral, noción que pasó a convertirse en los años siguientes en el paradigma consensuado por excelencia de las reformas agrarias latinoamericanas. En efecto, reforma integral es la expresión acuñada como una réplica al proceso de reforma radical que se ensayaba por aquel entonces en la Cuba revolucionaria; el término fue acuñado y consagrado en la Conferencia Mundial sobre Reforma Agraria, que bajo los auspicios de las Naciones Unidas, se celebró en Roma a mediados de los años sesenta. En esta ocasión la reforma integral se definió confusamente como una serie de medidas para eliminar los obstáculos que dificultan el desarrollo económico y social, los que se debían a falencias de la estructura agraria. Su objetivo fundamental habría de ser, entonces, afianzar la pequeña explotación familiar como punta de lanza de la modernización agrícola a través de un complejo programa de colaboración (educación, crédito, organización de cooperativas, etc.).

El tema de la reforma agraria está presente en la prédica y en las preocupaciones de los gobiernos de turno durante las décadas señaladas, adquiriendo en cada una de las instancias una particular y específica significación. La constante es la manifestación de diferencias y/o contradicciones 
entre el ámbito discursivo y el de las realizaciones concretas. Se advierte el permanente cuestionamiento al anacronismo de la reforma agraria, su escasa eficacia -desde el punto de vista del bienestar general y de la justicia social- derivando, en el mejor de los casos, hacia medidas alternativas -tipo desarrollo rural integrado-, impulsados como sucedáneos de la redistribución global y equitativa de la propiedad de la tierra.

Argentina no era ajena a este contexto, aunque con particulares perfiles en función de una explícita división entre una región rica y fértil que producía para la exportación y otra heterogénea, azarosa, en general, para el mercado interno, y por ende la concepción respecto a que no era necesaria una reforma agraria que provenía de los intereses de la región pampeana (Reboratti, 1985, pp. 8-9).

En este artículo el análisis se centra en las políticas sectoriales más ligadas a la región pampeana en función del peso que esta tiene en la economía nacional. La estrecha asociación entre la producción pampeana y el funcionamiento de la economía nacional hace que las medidas de tipo macroeconómico afecten directamente a su funcionamiento, y que las demandas sectoriales agropecuarias de esta región devengan en requerimientos directos sobre cambios en las políticas públicas (Barsky, 1993, pp. 50-53). ${ }^{2}$ En las otras economías regionales se produce una parte sensiblemente menor de bienes exportables, y una gran cantidad de materias primas y alimentos destinados al mercado interno. Se estipulan en estos ámbitos políticas por producto, ligadas a la fijación de precios, créditos, subsidios, formas de comercialización, sistemas de protección arancelarios. Y aquí intervienen activamente los gobiernos provinciales, generándose un campo de negociación de políticas mucho más específico. Las regiones extrapampeanas cumplieron durante todo este periodo un papel subordinado y de dependencia en relación con el centro de poder político y económico, persistiendo factores estructurales que determinaron el desarrollo desigual al interior de la estructura social de quienes residen en el ámbito extrapampeano, con particularidades específicas en cada caso. ${ }^{3}$

Sobre la base de estos procesos, nos proponemos rescatar el análisis histórico de diferentes instancias en torno a la necesidad de generar una reforma agraria en Argentina en el marco de las políticas de los diferen-

${ }^{2}$ Estas cuestiones se relacionan con la participación de la región pampeana, a saber: a) provee a la economía de una parte decisiva del ingreso de divisas, a través de las exportaciones agropecuarias, que permite el funcionamiento de otros sectores de la economía, b) genera la mayor parte de los alimentos para el mercado interno, determinando en gran medida el costo de la mano de obra y el nivel de salarios, afectando los límites inflacionarios, $c$ ) aporta, mediante el impuesto a las exportaciones y a los activos agropecuarios (inmobiliarios) una parte estratégica de recursos para el financiamiento del Estado (Barsky, 1993, p. 53).

${ }^{3}$ Para el acercamiento a estas características regionales en el periodo de tiempo aquí considerado, véase San Esteban (1980, cap. I). 
tes regímenes gubernamentales que se suceden a partir de la caída del peronismo en $1955,{ }^{4}$ en los que predominaron el absoluto pragmatismo y la constante de una ideología que rechazaba de plano la posibilidad de transformaciones en la distribución de la tierra, en favor de una línea de política productivista que, de hecho, desligaba el problema de los bajos rendimientos del tamaño y calidad de las explotaciones.

Es de destacar la presencia y fortalecimiento de regímenes autoritarios y represivos y la dominación que comenzaba a despuntar de las ideas neoliberales, que canalizaban las soluciones frente a la cuestión agraria fundamentalmente a través de la modernización capitalista y al predominio del mercado. Sin embargo, el proceso de la reforma agraria estuvo -con diferenciaciones y matices- en la agenda de los distintos regímenes que se sucedieron a partir del ocaso del peronismo, en franco distanciamiento de la naturaleza del proceso histórico de cambio centrado en la movilización de fuerzas sociales, ocluyendo la eliminación de conflictos en favor de métodos que se orientaron hacia un desafío institucional y político.

En síntesis, lo que nos proponemos es abordar desde la perspectiva histórica aquellas políticas públicas que intentaron erigirse en sucedáneas de un proceso de reforma agraria que implicara efectivamente la redistribución de la tierra. En todo el periodo considerado la penetración del capital extranjero se profundizó, y en alianza con los sectores terratenientes más concentrados, impulsaron una concentración crítica de tierras, capitales, mano de obra, sin incrementar mayormente la producción ni la productividad ni generar variaciones cualitativas en las relaciones de producción.

LAS PROPUESTAS DE REFORMA AGRARIA FRENTE

A LA HERENCIA DEJADA POR EL PRIMER PERONISMO

\section{Los planes de transformación agraria}

La política en torno a la propiedad de la tierra durante el primer peronismo, sobre todo la de arrendamientos, aseguró en principio un régimen de mayor estabilidad y de pérdida de peso de la libertad contractual, que

\footnotetext{
${ }^{4}$ El periodo abierto en 1955 con el golpe de Estado que puso fin al gobierno peronista se caracterizó por una profunda inestabilidad política. Ninguno de los tres gobiernos constitucionales del periodo -el de Arturo Frondizi (1958-1962), Arturo Illia (1963-1966) y nuevamente el peronismo (1973-1976) llegó a completar su mandato-. Los tres gobiernos militares de facto -revolución libertadora (1955-1958), revolución argentina (1966-1973) y el proceso de reorganización nacional que derroca al peronismo en 1976- fracasaron dramáticamente en sus objetivos y no generaron propuesta alguna ni política, económica o social.
} 
benefició al arrendatario tradicional -ligado estrictamente a la producción agrícola- proporcionándole un contexto propicio para una potencial capitalización; y favoreció también a aquellos propietarios mixtos que recurrieron al arrendamiento, en tanto cauce coyunturalmente auspicioso para la expansión de la actividad ganadera en incesante auge. ${ }^{5}$

En las políticas de arrendamiento como en las de colonización e impositiva sobre la gran propiedad, se advirtió la profundización de la legislación vigente desde comienzos de la década de 1940, antes de la llegada del peronismo al poder. El impacto de estas políticas generó un incremento de las tierras en propiedad, el retroceso del arrendamiento, modificaciones en el desempeño del terrateniente en función de la progresiva generalización del contratismo rural, la ampliación de las formas mixtas de propiedad, articuladas con la recomposición del latifundio ganadero.

Estas políticas respondieron, según los casos, a reivindicaciones y demandas de las diferentes organizaciones rurales; a iniciativas del Estado, tendentes a potenciar la participación regulatoria de la actividad económica, como reasignador de recursos a favor de la actividad industrial; a una precisa estrategia electoral y al empeño de neutralizar la conflictividad social -es decir, la cuestión social-y a asegurar la estabilidad y legitimidad política (Lázzaro, 2015).

A partir de la caída del peronismo -y en el contexto de una redefinición de las funciones económicas del Estado- las propuestas de transformación tienen como objetivo explícito promover la adquisición de tierras por parte de los arrendatarios; pero lo que en realidad se pretende es un más sólido y ajustado funcionamiento en el sistema de locaciones, del que definitivamente puedan erradicarse categorías tales como planificación e intervención, y desvanecer políticas que tengan que ver con las prórrogas,

\footnotetext{
${ }^{5}$ Perón, desde el periodo preelectoral, tendió a cubrir las expectativas de todos aquellos productores no propietarios (arrendatarios, minifundistas, ocupantes de tierras fiscales) a través de políticas de arrendamientos y de colonización. Durante los primeros años de la década de 1940 comienza a aplicarse la denominada política de emergencia en el marco de un intervencionismo estatal que tiende a equilibrar un sistema de inequidad en las relaciones sociales vigentes. Entre 1945 y 1946 se da una serie de disposiciones legales con el fin de llegar a una solución de fondo, enfatizando sobre dos aspectos esenciales: la baja en los cánones de arrendamientos y la prórroga de los contratos. Hasta que en 1948 se sanciona la ley que en su momento se considera como el nuevo estatuto orgánico sobre arrendamientos, cuyo principal propósito es poner fin a la estrategia -vigente hasta ahora- de dejar librada a las partes la voluntaria contratación, con exclusión del control que el Estado debe ejercer. En este marco, la ley introduce significativas modificaciones con manifiesto menoscabo de la libertad contractual: creación de las Cámaras Paritarias de Conciliación y Arbitraje, prolongación del plazo de los contratos, obligada participación del propietario en las contingencias de la producción al compartir los riesgos con el arrendatario, seguridad de un régimen de precio del arriendo justo para ambas partes y congelación de dicho canon, prohibición de los desalojos. Esta legislación fue ampliamente cuestionada y rechazada por las principales organizaciones corporativas que representaban a los productores más concentrados.
} 
los congelamientos y la suspensión de desalojos, aspectos nodales de la política sobre arrendamientos del primer peronismo.

$\mathrm{Al}$ finalizar el gobierno peronista se mantenían condiciones consideradas como una agobiante herencia: transitoriedad, vestigios de intervención, vencimiento de prórrogas. ${ }^{6}$ El gobierno que asumió en 1955 descalificó profusamente los resortes primordiales de la política peronista, fundamentalmente ante la exigencia de obtener una reconversión profunda. Según el general Eduardo Lonardi fue un gravísimo error del gobierno depuesto pretender una industrialización que exprimía al productor rural, dando lugar al desaliento del hombre de campo, y a la consiguiente crisis de las exportaciones a consecuencia de la caída del índice productivo (Transcripción de un informe, 1955, p. 6). En el contexto de una fuerte crítica global a las estrategias del peronismo, era posible destacar dos tipos de líneas dentro de la política económica de la última década, evaluadas entonces como especialmente desacertadas: la ilusión de elevar el nivel de vida sin un aumento real y efectivo de la producción; y la ilusión de expandir la industria pauperizando al campo, quedando sin resolver previamente el problema de las industrias básicas de la energía y el transporte; tanto en uno como en otro caso, el nivel óptimo de producción y la disponibilidad de saldos exportables se erigieron en condicionantes básicos, los que habían sido trastocados, precisamente, por la política del gobierno peronista (El pensamiento del gobierno, 1955, p. 30; véase también Alizón, 1956).

A partir de 1955 la tendencia respecto a la política sobre los arrendamientos rurales siguió encaminada por la senda de la transitoriedad, en tanto -depuesto ya el gobierno peronista- se continuaban sancionando diferentes instancias legales que prorrogaban los contratos vigentes. Pero contemporáneamente, a fin de 1955, se decidió la conformación de una comisión especial, cuyo cometido específico fue el estudio del régimen legal vigente en materia de arrendamientos y la propuesta de las reformas pertinentes más urgentes; los criterios fundantes a tener en cuenta reconocieron tres aspectos esenciales: el acceso del productor rural a la propiedad de la tierra, el retorno gradual a un régimen de libre contratación y la reestructuración de las cámaras de arrendamientos y aparcerías rurales, ${ }^{7}$ con miras a la organización de un fuero agrario.

\footnotetext{
${ }^{6}$ Para un acercamiento a la política agraria del peronismo en torno a la distribución de la tierra, véase Lázzaro (2015).

${ }^{7}$ Eran tribunales agrarios cuyo cometido central era considerar y juzgar los casos de divergencia que pudieran suscitarse a causa de la aplicación de la legislación, procurando la rapidez en los trámites a través del juzgamiento por parte de personal idóneo. Los tribunales estaban formados por representantes de propietarios y de arrendatarios -nombrados por el poder ejecutivo a propuesta de las entidades representativas respectivas $-\mathrm{y}$ presididos por un funcionario del Ministerio de Agricultura.
} 
La comisión quedó conformada a corto plazo, siendo su impulsor y protagonista el entonces presidente de la Cámara Central de Arrendamientos y Aparcerías Rurales Diego Ibarbia. ${ }^{8}$ Este propuso al Ministerio de Agricultura un plan de transformación agraria, que tendería a superar, en escaso tiempo, la situación generada por una prolongación casi ininterrumpida de medidas de excepción y de emergencia, causantes de un estado de tensión constante entre propietarios y arrendatarios.

La transformación -que debería realizarse con un alto sentido social, es decir, desprovista completamente de cualquier tipo de proceso que implicara "el quebranto o despojo de propietarios" - tenía como objetivo fundamental propiciar el arraigo de los actuales arrendatarios como propietarios de la tierra que ocupan, haciendo por fin realidad el principio recurrentemente mentado de "la tierra a quien la trabaja" (Ibarbia, 1956, fs. 2, 6-7, 12 y 21 ).

Independientemente de estos promisorios pronósticos el plan no alcanzó los resultados esperados, permaneciendo un panorama inquietante de disconformidades. Las sucesivas prórrogas en los contratos de arrendamientos, la continuidad en el congelamiento de los precios, el impacto del proceso inflacionario, son procesos que convergían para configurar una realidad preocupante en el ámbito agrario; escenario signado por discordancias que se originaban en los obstáculos para recuperar, por parte de los propietarios, la libre disponibilidad de sus explotaciones y para obtener una retribución proporcionada al costo de vida y al producido de sus tierras; y en el recelo e inseguridad de los arrendatarios frente a la factibilidad del vencimiento en masa de todos los contratos, lo que provocaría la imposibilidad de conseguir nuevas tierras para explotar.

Es significativa, al respecto, la convocatoria dirigida a los propietarios de campos arrendados con motivo del próximo vencimiento del plazo para responder a los arrendatarios que -en función de lo estipulado por el primer plan de transformación agraria- hayan ofrecido comprar el campo que ocupan (Sociedad Rural Argentina [en adelante SRA], 1957). Se aludía allí a la exigencia de lograr un alto porcentaje de arreglos, de estimular el espíritu de empresa, sobre la base de contar con la seguridad de que el derecho de propiedad será respetado. Y fue precisamente en defensa de ese derecho que se apelaba a la serenidad y buena voluntad de los propietarios, y fundamentalmente a su buena disposición para poder arribar a soluciones razonables para ambas partes, "ya que con su intransigencia harán ambiente propicio para que con el slogan de 'dar la tierra a quien la

\footnotetext{
${ }^{8}$ Hacendado e ingeniero agrónomo; integrante del Instituto de Colonización de la Provincia de Buenos Aires y de la Cámara Central de Arrendamientos; miembro de la Sociedad Rural Argentina e integrante de su comisión directiva en los periodos 1966-1967 y 1969-1970.
} 
trabaja', las fuerzas de izquierda aprovechen para solicitar medidas que hagan peligrar en forma absoluta el derecho de propiedad" (SRA, 1957, p. 8). Era el mismo sector propietario el que estimulaba este sistema negociado que propiciaba el acceso del arrendatario a la propiedad de la tierra; y ello porque era fuerte la certeza de que por esa vía no se arribaría seguramente a una modificación en la estructura de la tenencia de la tierra, sino que se alcanzarían mejoras en las normas de funcionamiento del sistema.

En julio de 1958 se intentó un nuevo recurso, a través de la promulgación de la Ley 14.451, con la que se procuró -nuevamente desde lo transitorio- conciliar las disidencias e incompatibilidades: frente a los requerimientos propietarios de restitución, no se menoscaban las exigencias de una realidad social protagonizada por el aún gravitante núcleo arrendatario.

Ambas instancias legales, la de Diego Ibarbia, por un lado, y esta de 1958, denominada segundo plan de transformación agraria ofrecían soluciones alternativas y complementarias a los variados aspectos del problema de la locación rural. Este segundo plan se concretó formalmente ante las situaciones de desequilibrio en el ámbito rural y dentro de las medidas específicas sostenidas por los legisladores de la UCRI; y se enfatizó sobre la necesidad de ejecución de la reforma agraria, a través de la colonización incorporando los latifundios, las tierras de propiedad de sociedades anónimas, las irracionalmente explotadas y la tierra pública. ${ }^{9}$

Es pertinente destacar en este marco algunos antecedentes que rozaron de cerca la política agraria del desarrollismo que incorporó Arturo Frondizi. Este asumió como presidente a comienzos de 1958, y no tardó en manifestar una abierta actitud contradictoria respecto a lo que habían sido sus propuestas preelectorales y el programa de Avellaneda de $1945 ;{ }^{10}$ si bien este no había sido modificado, sino incorporado a la plataforma electoral del radicalismo en agosto de 1957, la Unión Cívica Radical In-

${ }^{9}$ Véase Diario de sesiones de la Cámara de Senadores, 26 de junio de 1958, t. I, 17a. sesión ordinaria, pp. 521-524. El mensaje que acompaña al proyecto de ley es refrendado por el presidente Frondizi, el ministro de Economía Emilio del Carril y el secretario de Agricultura y Ganadería, Bernardino Horne, quien sustentaba la línea más reformista dentro del gabinete.

${ }^{10} \mathrm{El}$ documento fue inicialmente suscrito por Frondizi, que fue su redactor, y por otros militantes significativos, tales como Moisés Lebenshon, Crisólogo Larralde, Ricardo Balbín, Francisco Rabanal, Oscar Alende, Aritóbulo Araoz de Lamadrid, Celestino Gelsi y Luis Mac Key. En este programa, se plantearon -entre los aspectos esenciales- que la Unión Cívica Radical era la herramienta por excelencia para instaurar una democracia política, económica y social en Argentina; que era imprescindible levantar todo impedimento para la libre manifestación de los derechos constitucionales; que resultaba imperioso el restablecimiento de la unidad partidaria, pero sobre la base de una vuelta a la doctrina y una reorganización que ubicara en los lugares de conducción a hombres con probada trayectoria principista; a la vez que se reivindicaba el régimen republicano, representativo, federal y parlamentario, fundado en el voto secreto, universal y obligatorio. 
transigente (en adelante UCRI) introdujo cambios sustanciales. ${ }^{11}$ Frondizi fue extremadamente cauto al no insistir sobre aspectos que pudieran afectar negativamente a los sectores más tradicionales y concentrados del poder: es así como se dejan de lado aspectos sustanciales que el Programa de Avellaneda contenía, tales como la reforma agraria inmediata y profunda y la nacionalización de los servicios públicos, de los monopolios y del petróleo. De este modo, desde la reforma agraria inmediata y profunda -tal como se propuso en el mencionado programa- se va transitando hacia otra concepción, según la cual la estructura agraria atrasada no reconoce su causa en el hecho de que la tierra pertenezca a uno o a mil propietarios, sino en que se mantenga al margen de las formas capitalistas avanzadas de producción. El punto decisivo fue, entonces, el incremento de la productividad, vía incorporación de capitales y de tecnología, lo que se tradujo en una proposición desviada del primigenio plan gubernamental.

A pocos meses de aprobado el segundo plan de transformación agraria, la comisión directiva de la Sociedad Rural Argentina solicitó al presidente Arturo Frondizi el veto parcial de la nueva ley de arrendamientos rurales, en función de la alarma provocada, y por "la desfavorable repercusión en el orden interno e internacional, [en tanto estaban afectados] fundamentales principios federales y constitucionales concernientes al derecho de propiedad [y a la] igualdad e inviolabilidad de defensa en juicio" (SRA, 1958, p. 6)

Y concluía con una sagaz recomendación:

desvirtuar el concepto erróneo de que la tierra útil se mantiene concentrada en pocos y poderosos privilegiados que la conservan sin llegar a los rindes adecuados por falta de interés personal [...] La realidad es otra [...] Las explotaciones rurales mantienen el interés de grandes y pequeños inversores, y en toda la zona fértil se hallan en estado de producción, sin otras limitaciones que las que emanan de planificaciones estatales equivocadas (SRA, 1958, p. 13).

Dentro de los propósitos contemplados en los planes y medidas específicas por parte de los legisladores nacionales de la UCRI gobernante la solución de fondo se lograría mediante "la ejecución de la reforma agraria, procediendo a la colonización del país y a la radicación definitiva del trabajador mediante la adquisición de la propiedad de la tierra que trabaja [...] A tal efecto, será menester incorporar a los planes de colonización,

${ }^{11}$ El tradicional partido de la Unión Cívica Radical, a causa de situaciones controvertidas generadas en diferentes ámbitos políticos, se escinde a partir de 1957, por un lado la Unión Cívica Radical del Pueblo, liderada por Ricardo Balbín, y por otro, la Unión Cívica Radical Intransigente, encabezada por Arturo Frondizi. 
los latifundios, la tierras de propiedad de las sociedades anónimas y las ociosas o irracionalmente explotadas, y la tierra pública". ${ }^{2}$

A los pocos años del intento de aplicación de estos planes de transformación agraria, fue evidente lo reducido de su alcance y el casi total fracaso de los propósitos planteados en su momento, constituyéndose en el factor limitante de más gravitación -a juzgar por los distintos programas intentados-: el financiero; el exagerado valor venal de la tierra se manifestó como fundamento de tal situación, frecuentemente asociado a una baja rentabilidad de la empresa agropecuaria -en gran parte a causa de la sobrevalorización de la propiedad rural-. A esta realidad se acopló, por un lado, la política de arrendamientos efectivamente en vigencia, con sucesivas prórrogas que no eran lo suficientemente previsoras -se argumentaba desde el gobierno- como para que a través de su esquema operativo contribuyera a un uso más racional del suelo, comprometiendo seriamente la productividad; y, por otro, los problemas emergentes de la escasez de crédito bancario que dificultaba los objetivos de la transformación agraria.

En 1959 la organización autodenominada Liga Argentina para Promover la Recuperación Económica Nacional (en adelante LAPREN), abiertamente consustanciada con los intereses de los propietarios más concentrados, dio a conocer una publicación "dirigida a las fuerzas vivas del país [sobre el tema de la reforma agraria, que] se ha convertido en tema político y ofrece campo proficuo para la acción propagandística de grupos extremistas ajenos a nuestras costumbres e instituciones" (LAPREN, 1959). ${ }^{13}$ Tres fuerzas sociales, según esta entidad, estaban en pugna, en virtud del importante despliegue del tema de la reforma agraria en los diferentes ámbitos políticos. En primer lugar, las "entidades rurales más representativas", que perciben el perjuicio que se avecina para la economía agropecuaria, en tanto se promovería la expropiación de campos en plena explotación, sin tener en cuenta los valores venales, sino tan sólo los promedios de pro-

\footnotetext{
${ }^{12}$ Expresiones del senador Rodolfo Weidman, de la UCRI, al fundamentar un proyecto sobre prórrogas de arrendamientos y de aparecerías rurales y sobre suspensión de desalojos, en Diario de Sesiones de la Cámara de Senadores, 14 de mayo de 1958, t. I, 4a. sesión ordinaria, p. 136.

${ }^{13}$ La publicación está firmada por Carlos Rubio Quintana, como director de la revista $E s-$ tancias Argentinas y con estrechas relaciones con las corporaciones de grandes propietarios. Nos detenemos en el contenido de esta breve publicación porque expresa la opinión, desde un punto de vista más informal que el de las corporaciones agrarias más tradicionales que mantenían una relación más continua con los poderes públicos de turno. En el caso de LAPREN, la mayor preocupación estaba centrada en la posibilidad de la expropiación y sus posibles derivaciones. No hemos hallado hasta el momento otra instancia en la que esta organización se haya expresado, lo que implica que se constituyó informalmente en función de esta coyuntura particular signada por los planes de transformación agraria. La reforma agraria no era considerada como una actividad permanente sino que se trataba de una intervención excepcional para resolver una cuestión agraria, la que existe cuando las relaciones económicas, sociales y culturales son un impedimento para el desarrollo (Groppo, 1977). En este marco quizá se explique la exigüidad de esta organización.
} 
ductividad. En segundo, el sector de los arrendatarios y aparceros, "que evidentemente buscan el afincamiento de su familia en el campo que explota o en otro similar", y que por lo tanto se manifestaban a favor de una transformación en el sistema de tenencia de la tierra. Y, en tercero, había otro sector, "que es el principal interesado en que el problema sea resuelto con soluciones de alto nivel: ese tercer sector es el país" (LAPREN, 1959, pp. 5-7). Los aspectos que se abordan en LAPREN (1959, pp. 5-15) son los mercados internacionales, las amplias desventajas del minifundio, la incidencia fundamental del progreso técnico aplicado al ámbito rural, incluso como factor de mantenimiento de la paz social, la preeminencia del sostenimiento de la unidad de producción por sobre la unidad familiar de subsistencia; todo ello como fundamento de una estricta oposición a todo aquello que de alguna manera amenace la estructura de la propiedad o promueva la expropiación de campos.

Estas inquietudes estaban lejos de plasmarse en la realidad por la mayor moderación y flexibilización de las propuestas reformistas en los primeros años de la década de 1960 y, porque también las iniciativas encaradas por el gobierno de la provincia de Buenos Aires, al filo de los años cincuenta, no se orientaron hacia una alteración profunda en la estructura de tenencia y en el sistema de relaciones sociales; y en definitiva se limitaron a proponer una redistribución de la propiedad y del ingreso agrícola -a través de procesos de colonización y de parcelación, y de la presión de políticas tributarias- $y$ un ajuste en las normas del funcionamiento institucional. En efecto, dentro de la misma UCRI, algunos sectores se mantuvieron en la etapa reformista por un periodo más extenso, es el caso del gobierno de la provincia de Buenos Aires, encabezado por Oscar Alende. ${ }^{14}$

Independientemente de algunas concreciones de expropiaciones en el ámbito de la provincia de Buenos Aires (Blanco, 2007), lo cierto es que el proceso de reforma agraria se vio limitado y constreñido a las líneas de acción ya tradicionales desde la formulación de los primeros planes de transformación agraria. Según José Martínez de Hoz ${ }^{15}$ (1965) "la acción colonizadora debe orientarse no a la simple parcelación de campos que se encuentran en plena explotación, sino a la incorporación de nuevas tierras incultas al proceso productivo, las que se encuentran situadas, en su mayor parte, fuera de la región pampeana".

En 1960 el segundo plan fue modificado parcialmente, con el específico propósito de tratar de incentivar las potenciales operaciones de com-

${ }^{14}$ Oscar Alende participó desde la década de 1940 en cargos públicos dentro de la UCR. Fue presidente del bloque radical en 1957, cofundador de la UCRI con Arturo Frondizi en el mismo año, y gobernador de la provincia de Buenos Aires entre 1958 y 1962, véase Lázzaro (2015).

${ }_{15}$ Importante ganadero de la provincia de Buenos Aires, ligado estrechamente con las corporaciones agrarias más representativas en el ámbito rural y vocero destacado de la SRA. 
praventa, a través, fundamentalmente, de exenciones impositivas que involucraban tanto al vendedor como al comprador, el que necesariamente debía ser arrendatario de aquel, con alicaídos alcances también.

La política agraria durante el periodo del gobierno de Arturo Illia ${ }^{16}$ no exhibía sustanciales transformaciones, en función de las condiciones socioeconómicas y político-institucionales internas, que condicionaron el devenir de este efímero gobierno. La política agraria tuvo claros objetivos orientados al aumento de la productividad, alejados en todo momento de propósitos distribucionistas que pudiesen afectar la disponibilidad privada de la tierra. Se proponía la reforma agraria, pero en todos los casos con el fin de evitar la dinámica especulativa en materia de tierras y de superar la subutilización de la capacidad productiva de la misma. En el Plan Nacional de Desarrollo ${ }^{17}$ así como en otras instancias de explicitación de la orientación oficial, fue constante la referencia a una política agraria integral, que en definitiva se encaminaba a poner en práctica una serie de medidas tendentes a eliminar los obstáculos que dificultaban el desarrollo económico y social, muchos de los cuales se atribuyeron a deficiencias en la estructura agraria. De hecho el desarrollo rural integrado contenía una serie de estrategias alternativas, que se impulsaban precisamente como sucedáneas de la redistribución de la tierra.

Dos fueron las líneas fundamentales en lo que atañe a la política agraria, ambas cercenadas en su aplicación. Una de ellas es la ley de arrendamientos, que se limitó en su formulación final a constituirse en la continuidad de lo que habían sido los planes de transformación agraria a partir de 1957. La reforma agraria quedaba limitada a una elevación del nivel de vida a través de la mayor productividad en función de la tecnología, en cuyo contexto la tierra es un elemento más, ciertamente no el más importante. El desafío no era ya dar la tierra a quien la trabaja, sino producir más a menores costos, con fuertes criterios de eficiencia y de productividad, con un estricto sentido de empresa. Estos eran también los propósitos que animaban la otra iniciativa política, relacionada con el proyecto de impuesto a la renta normal potencial. Mayor productividad, aumento tecnológico, acceso a la propiedad de la tierra, modificaciones impositivas, impulso crediticio: todo ello orientado al fortalecimiento del ámbito agrario, en función de las necesidades del mercado interno y de la demanda de saldos exportables que permitan una consolidación del sector industrial, al

${ }^{16}$ Illia accedió a la presidencia como candidato de la UCRP con sólo $25 \%$ de los votos, legitimidad escasa que pronto derivó en un pronto desgaste generado por la articulación de intereses económicos, sociales, políticos y militares.

${ }^{17}$ Importante documento en torno a la planificación en Argentina, cuya presentación definitiva se realizó en 1965 y por tanto con pocas posibilidades de aplicación. 
que se lo ubicaba en una posición de desarrollo armónico en relación con la economía rural.

Hubo confrontaciones con las corporaciones que aglutinan a los grandes propietarios, los que sistemáticamente se opusieron tanto a la ley de arrendamientos como al proyecto de transformación impositiva. Pero más allá de las críticas puntuales, el núcleo de la confrontación giró alrededor de lo que consideraban una acción estatizante del gobierno de Illia, y a las falencias que este demostraba en tanto abandonó tareas específicas para el sector agrario que iban más allá de alcanzar la incentivación por vía del impuesto a la renta normal potencial (precios, costos de producción política cambiaria e impositiva, entre otras).

En 1963, y con el expreso objetivo de "continuar y ampliar el proceso de transformación agraria para convertir en propietarios al mayor número posible de arrendatarios" (SRA, 1966, p. 82), pero esencialmente para arribar de manera definitiva a un sistema de descongelación del régimen de arrendamientos, se sancionó el tercer plan de transformación agraria.

Estos sucesivos planes -sin resultados relevantes a la vista y con algunas divergencias en las estrategias a implementar- convergían en un objetivo común: lograr un funcionamiento más preciso, mejor articulado y más flexible del sistema vigente, que encauce el tránsito hacia otro rumbo en el que las intervenciones estatales (congelamientos, prórrogas, planificaciones) se diluyeran definitivamente. Lejos estaban los distintos planes de transformación agraria de intentar modificar el sistema de tenencia, redistribuir el ingreso, poner en actividad tierras ociosas o contribuir al incremento del empleo rural, sino que se redujo a una operación táctica de colonización, modernización tecnológica y redistribución de ingresos por medio de políticas de regulación, de rentas y aparcerías (García, 1973, pp. 64-65).

Si bien era indiscutible que continuaba el proceso de incremento de la superficie bajo el régimen de propiedad, no indicó la conversión lineal de arrendatarios en propietarios, sino que se articulaba con todo un proceso de transformación y complejidad de la base productiva rural, y por ende también de la estructura social del ámbito agrario. ${ }^{18}$

Desde mediados de la década de 1950 y hasta comienzos de los años setenta, la ideología liberal y el desarrollismo se constituyeron en el marco

\footnotetext{
${ }^{18}$ Existen varias interpretaciones historiográficas en torno al ulterior destino de los ex arrendatarios: acceso a la propiedad de la tierra por parte de pequeños y medianos productores lo que habría generado un proceso de farmerización en la región pampeana sobre la base de diferentes estrategias (Balsa, 1998; Flichman, 1978; Forni y Tort, 1984); abandono de las explotaciones o desalojos de los arrendatarios y reconstitución de unidades productivas de mayor tamaño (Slutzky, 1968); intensificación del trabajo familiar en las explotaciones agrícolas arrendadas, reducción del área de las mismas, ante el condicionamiento que obliga a reducir costos (Mascali, 1986).
} 
imprescindible para la nueva inserción dependiente de la economía argentina en la fase de la internacionalización del capital bajo la hegemonía estadunidense (Paz, 1985, pp. 56-62). Y durante todo este periodo -con diferentes características, propósitos y consistencias o resistencias- los intentos en favor de una reforma agraria fueron permanentes, imbuidos en todos los casos de un perfil estrictamente pragmático.

La producción agraria pampeana continuó ocupando un lugar central en el sostenimiento del sistema, en tanto conservaba el doble papel estratégico de ser, por un lado, la principal fuente de divisas para pagar las importaciones y solucionar los desequilibrios de la balanza de pagos, $y$, por otro, responder a los requerimientos del consumo del mercado interno. Pero los niveles de crecimiento de la producción no permitían aún en este momento satisfacer ambas demandas, lo que explica que las crisis del sector externo, al desequilibrarse la balanza de pagos, se convirtiesen en una constante.

Las soluciones que se proponían desacreditaban aquellas concepciones según las cuales la tenencia de la tierra, concentrada en manos de la oligarquía terrateniente, era el elemento fundamental del problema agrario argentino; procuraban considerarlo dentro de la problemática general del subdesarrollo, siendo el objetivo transformar las explotaciones agrarias en verdaderas empresas, y por tanto "la cuestión agraria es un problema de incremento de la productividad, la que se resuelve con la incorporación de capitales y de tecnología" (Frondizi, 1965).

En la misma línea, Ignacio C. Zuberbülher ${ }^{19}$ sostenía (SRA, 1960, pp. 556-557) como paradigma de las concepciones dominantes en la época, que la reforma agraria proyectada por la provincia de Buenos Aires a la que aludimos antes, era de corte marxista y totalitaria, en tanto atentaba abiertamente contra el derecho de propiedad. Acordaba con la necesidad de una reforma en los sistemas de explotación agraria, con miras al acrecentamiento de la producción, pero rechazaba la reforma agraria en tanto proyecto comunizante, abogando por una progresista colonización: la auténtica colonización que auspician los conservadores; para ello es preciso dejar los campos actualmente explotados en manos de sus dueños, e instalar colonias en los campos fiscales del Estado -el mayor latifundista argentino-, en explotaciones que se ofrezcan libremente en venta, al tiempo que ha de apoyarse financieramente la instalación de colonias en los campos inexplotados de grandes zonas del país. En este marco era evidente que

${ }^{19}$ Importante ganadero de la provincia de Buenos Aires, integrante de la comisión directiva de la Sociedad Rural Argentina entre 1954 y 1960; presidente de la Corporación Argentina de Aberdeen Angus durante gran parte de la década de 1960; socio fundador de la firma Ricardo e Ignacio Zuberbülher, de administración de propiedades urbanas y rurales. 
reducir el tamaño de las explotaciones no ofrecía soluciones como sí lo hacían la eficiencia, la tecnología, el tema de los costos y de la productividad.

Durante las décadas de 1960 y 1970 se generaron procesos de intensificación en la agricultura de varios países latinoamericanos: en efecto, muchos gobiernos estimularon la modernización del sistema de hacienda a través de medidas tales como créditos subsidiados para la compra de maquinaria, ganado de mejor calidad, fertilizantes y programas de asistencia técnica, con lo que se capitalizaban sus empresas a través del mejoramiento de las tierras, la infraestructura, la mecanización. Este proceso de modernización podría caracterizarse como una vía latifundista al capitalismo agrario, ya que los mismos latifundistas transformaron sus grandes explotaciones en fincas capitalizadas comerciales orientadas a la ganancia. En el caso de Argentina, la reforma agraria y sus propuestas sucedáneas (transformación, promoción, desarrollo rural tecnocrático entre las principales) estuvieron motivadas por determinadas condiciones económicas, pero es preciso aseverar que en ningún caso se trató del intento de un proceso administrativo o aun económico, sino de un proceso esencialmente político, en tanto los intereses en juego enfrentaban a clases sociales determinadas. De allí que, más allá de los programas conceptualmente enunciados, lo que prevaleció fue un claro sesgo pragmático.

Pues si bien las variables económicas pueden ser definidas sobre la base de conceptos derivados de los principios generales de la economía, el comportamiento de estas variables, en estos casos, estuvo condicionado por parámetros institucionales cuyo conocimiento exigía un estudio particular y específico de la realidad social (Furtado, 1966).

\section{REFORMA DEL RÉGIMEN AGRARIO A TRAVÉS \\ DEL BINOMIO ARRENDAMIENTOS-IMPUESTO A LA RENTA PRESUNTA}

El régimen militar instaurado en Argentina en 1966 tuvo como objetivo consolidar la hegemonía del sector industrial de la gran burguesía, liderado por el capital extranjero y las grandes firmas multinacionales. El plan económico de A. Krieger Vasena ${ }^{20}$ se propuso incentivar la modernización, otorgándole al Estado el papel fundamental de erigirse en el instrumento directo de la fracción transnacional del capital.

Durante el gobierno del general Juan C. Onganía se sancionó la ley que crea el impuesto a las tierras aptas para la explotación agropecuaria, consistente en un porcentual fijo de su valuación fiscal y no venal, con

${ }^{20}$ A. Krieger Vasena se desempeñó como ministro de Economía entre 1966 y 1969, durante el gobierno de facto de Onganía. 
carácter de anticipo del impuesto a los réditos, lo que amerita a presumir más razones de índole fiscal que social. En el contexto de su promulgación, el entonces secretario de Agricultura y Ganadería, Lorenzo Raggio, afirmaba que la fórmula arrendamiento-renta presunta era el eje de la reforma en el régimen agrario (Lázzaro, 2005, pp. 332-334). Nuevamente la apelación a la reforma agraria, en el marco del intento de instauración de un impuesto al valor potencial de la tierra, cuyo principal propósito estaba asociado a lograr mayor productividad y eficiencia, eludiendo todo proceso redistributivo.

La participación del sector agrario en el contexto de un programa económico sostenido por la alianza entre los sectores más concentrados del capital nacional y del capital extranjero fue significativa, en tanto se manifestaba como el generador más sólido de las divisas. Pero dada su situación de subordinación en relación con los intereses de las empresas transnacionalizadas, se requería la acción de un Estado con la suficiente capacidad política y administrativa para diseñar, poner en práctica y controlar las políticas públicas oportunas, lo que se tradujo en una particular forma de intervención estatal (O’Donnell, 1982, pp. 36-38). Como resultado de esta ola de inversiones extranjeras en la industria se modificaron las relaciones de fuerza de la sociedad, sufriendo la clase dominante argentina grandes cambios: ahora el capital extranjero será un nuevo agente socioeconómico en el país; esta burguesía internacional o internacionalizada es la que va a liderar sobre el empresariado argentino. Del resultado de este proceso y del nuevo papel del Estado, emergerá una nueva capa social en relación con las otras capas dominantes en el control del aparato del Estado; esa capa encontró en Krieger Vasena a su mayor exponente (Kossacoff y Azpiazu, 1989, p. 159; Quiroga, 1985, pp. 63-64).

El agro debía encarar su modernización a través de estrategias que derivaran en organizaciones empresariales eficaces. Las corporaciones de grandes propietarios agrarios apoyaron al comienzo el plan económico de la revolución argentina, en tanto promovía la productividad y la eficiencia, el apoyo a la empresa privada, la libertad económica y el respeto a las condiciones del juego del libre mercado.

Pero también exteriorizaban una realidad plagada de dificultades: incremento en los costos de producción; precios agropecuarios casi inmóviles; iliquidez generalizada; inseguridad respecto a la propiedad de la tierra por la vigencia casi ininterrumpida de una dinámica de arrendamientos rurales fundada en las continuas prórrogas de los contratos, y carencia de una política agropecuaria nacional coherente y permanente. Resistieron las retenciones a las exportaciones, y el tan vapuleado impuesto a la tierra. Su propósito era obtener una creciente producción con reducción de 
costos, pero dentro de la lógica de la empresa agropecuaria que inevitablemente suponía el logro de una mayor rentabilidad, sin la que no podía subsistir.

Más allá del grado de concreción que tuvo la puesta en práctica de estas políticas estatales sobre la estructura socioeconómica agraria, ellas demostraban la fuerte presencia de una gestión normalizadora, a través de la capacidad del Estado para intervenir selectivamente en la actividad económica y normalizar precisamente su funcionamiento (O'Donnell, 1982).

Los terratenientes tradicionales fueron favorecidos por algunas medidas estatales (como el fin de la legislación de emergencia de los arrendamientos que se retrotraía a la época del primer peronismo), pero al mismo tiempo relativamente perjudicado por un sistema de devaluación compensada por cargas impositivas. Se devolvía la seguridad jurídica y la libre disponibilidad de sus tierras a los propietarios arrendadores, pero simultáneamente estos quedaban al margen de los beneficios de la política, que amparaba esencialmente a los sectores industriales asociados al capital extranjero y al sector financiero.

El Estado se empeñó en suprimir todas aquellas protecciones de naturaleza social o política que pudieran obstruir la libre competencia o la formación de capital, siendo este el contexto en el cual se inscribe la legislación relativa a arrendamientos. Pero también necesitó realizar una serie de intervenciones estratégicas con el fin de obtener recursos monetarios, imprescindibles para dinamizar el plan económico en vigencia. De allí el mecanismo financiero implantado, que reconocía uno de sus pilares fundamentales en las imposiciones al sector agropecuario. Las retenciones a las exportaciones funcionaban no sólo como un mecanismo de control de los precios internos, sino también, y en mayor grado, como una fuente de recursos para el Estado; pero además, al impactar sobre uno de los sectores más beneficiados por la devaluación, se erigió en un destacado instrumento de redistribución de ingresos.

La política sobre arrendamientos rurales y la referida al impuesto a la renta normal potencial -que en realidad se constituyó en un impuesto sobre las tierras aptas para la explotación agropecuaria- conformaban un binomio estrictamente funcional, según el discurso oficial. Independientemente del objetivo fiscal del impuesto a la tierra, es de destacar que se lo concibió además, como una estrategia que tendió a evitar que la tierra quedase fuera del alcance del productor eficiente, y que se convirtiese tan sólo en un bien de especulación. Se aseguraba que los campos desocupados por los arrendatarios mantendrían o aumentarían su nivel de eficiencia productiva. Por tanto la combinación arrendamiento-impuesto a la tierra despuntaba como el eje de la reforma en el ámbito agrario (Funes, 1967, 
pp. 12-14). ${ }^{21}$ Más aún, se concebía a estas políticas como estrategias convenientes para generar la restitución de la movilidad social en el campo, a través de un mecanismo de promoción de los más aptos. Discurso bastante alejado de una acción concreta de gobierno, liderado por la gran burguesía industrial, que, en nombre de la tan mentada normalización no escatimó esfuerzos en disciplinar a los asalariados y a los productores agropecuarios menos concentrados, como método para destrabar cualquier tipo de obstáculo que dificultara el proceso de acumulación. ${ }^{22}$

Es de destacar la posición constantemente defensiva de las corporaciones de grandes propietarios territoriales que, en un estado de manifiesta alteración y desasosiego por el recurrente tema de la reforma agraria, atinaron a profundizar el proceso de aglutinación, y a centrar sus propuestas en planes de promoción rural sobre la base de la tranquilidad en el orden, pareciendo ignorar, por el momento, la distancia abismal existente entre las leyes y los procesos de reforma agraria. ${ }^{23}$

Lo invariable eran las diversas formas de tergiversación de las iniciativas redistributivas, siendo el caso más frecuente desde el ámbito de los propietarios más concentrados, el de presentar la colonización de nuevos territorios como la fórmula ideal para superar los problemas generados por una distribución asimétrica de la propiedad. Esta estrategia parecía prescindir de las características cualitativas de las tierras, por lo general marginales, con escasa capacidad económica, incomunicadas o lejanas a los centros de consumo, procesos que derivarían en un "darwinismo social que elimina al débil, al humilde, con beneficio del poderoso y grandes traumas que a menudo son factores de una violencia que la ausencia del Estado impide contener" (Breton, 1994, p. 40).

${ }^{21}$ Primera Plana, 28 de marzo de 1967, núm. 222, pp. 48-49.

${ }^{22}$ En los tramos finales del gobierno de la revolución argentina, el entonces secretario de Agricultura y Ganadería, Ernesto Lanusse, envió al poder ejecutivo una propuesta para implantar un impuesto nacional sobre el valor fiscal de las tierras, que reemplazaría al impuesto a los réditos y a todo tributo susceptible de sustitución. Los considerandos señalaban los perjuicios derivados de tierras insuficientemente explotadas, así como la necesidad de castigar al productor ineficiente y premiar al eficiente. El nuevo impuesto se implantaría a partir de 1973. Sin embargo, a finales de 1972, desde la Subsecretaría de Hacienda se declaró la imposibilidad de actuar dentro del plazo previsto "por inconvenientes técnicos y por falta material de tiempo" (El impuesto como impulsor, 1984, pp. 46-47).

${ }^{23}$ En 1960, Pablo Hary (1961), importante ganadero de la provincia de Buenos Aires, opone a la reforma agraria la política de promoción rural, cuyos condicionantes fundamentales son la tranquilidad en el orden que acabaría con la inestabilidad, las periódicas amenazas de expropiación o de nuevas cargas impositivas, y la profundización de los aspectos técnicos, a lo que denomina explosión técnica. 
EL PERONISMO DE LA DÉCADA DE 1970:

¿LA TIERRA PARA QUIEN LA TRABAJA?

En 1973 retornó el peronismo al poder, enmarcado en principio en un intento de clausurar la crisis orgánica abierta a partir de fin de los años sesenta y con el propósito de recuperar el poder legitimador del Estado recreando un sistema político que tenía como uno de los desafíos centrales controlar la conflictividad social (Nicanoff y Pita, 2006).

Respecto al programa económico y social cabe destacar algunos ejes centrales, presentes en el discurso inicial: la política agraria, que combinaba las transferencias de ingresos hacia otros sectores de la economía, con las propuestas de modernización para incrementar la producción y los saldos exportables; las medidas tendentes a favorecer el desarrollo industrial y a las empresas de capital nacional; la mejora de la situación de los sectores asalariados; y la restricción de la actividades de las empresas transnacionales, considerando que habían sido tratadas de manera privilegiada por los gobiernos anteriores. Todos estos procesos implicaban el incremento de la intervención estatal en el ámbito socioeconómico y político-institucional (Sidicaro, 2002, p. 117). Pero ya el modelo de industrialización por sustitución de importaciones de la década de 1940 había llegado a su fin, y la situación internacional vigente condicionó de manera significativa el lábil intento de reeditar aquel modelo (Lázzaro, 2013a).

El contexto, tanto nacional como internacional, difería ampliamente del vigente durante el primer peronismo; y el sector agrario no estaba en condiciones -como en los años de la década de 1940- de realizar transferencias de su excedente hacia la industria y el ámbito urbano, lo que se consideró un punto de vista válido para la generación de políticas sectoriales que incrementaran la producción y la productividad agropecuaria. El logro de este propósito impuso la urgencia de operar sobre el sistema de tenencia de la tierra y la subutilización de la misma como factor productivo.

El programa se basaba en el principio de que la tierra debe ser para quien la trabaja y un bien de producción y no sólo de renta y especulación, para lo cual debían erradicarse los latifundios improductivos y los minifundios antieconómicos, facilitando el acceso a la propiedad a auténticos productores, reorientando la política de colonización en tierras fiscales y promoviendo el desarrollo de unidades familiares de producción y unidades comunitarias de trabajo rural. La aplicación de un impuesto a la renta normal potencial de la tierra era considerada el instrumento vital para obtener aquellos objetivos, en tanto castigaría al productor ineficiente y a la especulación, a favor de la productividad (Lattuada, 1986, p. 215). 
En las diferentes y sucesivas instancias de programación y concertación se advertía la referencia a lo que denominaban reforma agraria integral, la que contendría aspectos fundamentales tales como el acceso a la propiedad de la tierra por parte de los productores directos; la difusión de unidades familiares de producción; la erradicación de los latifundios y minifundios improductivos; la reorientación de la política de colonización en tierras fiscales; la difusión del cooperativismo en todas sus formas; el fomento de unidades comunitarias de trabajo rural; la implementación del impuesto a la renta normal potencial, entre otros.

En septiembre de 1973 -en el marco de un periodo caracterizado por los pactos, acuerdos, concertaciones, planificaciones, etc.- se firmó el Acta de Compromiso del Estado y los Productores para una Política Concertada de Expansión Agropecuaria y Forestal, entre integrantes del equipo económico y los representantes de los sectores relacionados con la producción agropecuaria. El gobierno nacional y los productores se imponían la realización de esfuerzos mancomunados a fin de llevar a cabo una política concertada, destinada a incrementar y diversificar la producción, armonizándola con el desarrollo integral del país (Acta de Compromiso, 1973, pp. 8-14).

La planificación concertada era el medio para una efectiva participación de todos los interesados en el quehacer rural, a fin de que los programas adoptados cuenten con el compromiso y apoyo solidario de quienes eran responsables de los mismos, tratando de dejar en claro que la programación no excluía la concertación, sino que por el contrario la perseguía. El Acta de Compromiso del Campo, como generalmente se lo denominó, fijó las bases de un programa de auténtica revolución en paz para el campo, ya que el Estado aseguraba a los productores asistencia financiera y tecnológica, vivienda y acceso a la propiedad de la tierra, a cambio del compromiso de incrementar la producción dentro de un programa de largo alcance (Presidencia de la Nación, 1975, pp. 170-171).

Todos estos propósitos tuvieron un tratamiento más sistematizado en el denominado Plan Sectorial Agropecuario 1974-1977, elaborado por la Secretaría de Agricultura y Ganadería de la Nación, a cargo del ingeniero Horacio Giberti, secretario de esa cartera durante los gobiernos de Héctor Cámpora y de Juan Perón. Se proponía realizar la concertación en el sector agrario a través de la puesta en práctica de objetivos precisos, que reiteraban contenidos previos. De estos propósitos, los que iban a generar conflictividad con los sectores agrarios más concentrados, fueron los relativos a la tenencia de la tierra y al régimen impositivo.

Respecto a la política impositiva, los fines a lograr eran el aumento de la producción, el incremento de la eficiencia productiva y la recaudación acorde con la capacidad imponible de los contribuyentes del sector. Sobre 
esta base, la política impositiva para el agro se basaba fundamentalmente en el impuesto a la renta normal potencial de las explotaciones agropecuarias, sancionado por el Congreso Nacional en septiembre de $1973 .{ }^{24} \mathrm{Tal}$ como surgía de su denominación, el impuesto consistiría en determinar la renta sujeta al impuesto a las ganancias (antes impuesto a los réditos) en las explotaciones agropecuarias, basándose en los resultados de una explotación media de similares características a la del contribuyente; de esta forma el impuesto incidiría como una suma fija por hectárea, independientemente de la intensidad con que el predio fuese explotado. La tasa a aplicar sobre dicha renta era progresiva y dependía del monto total de la renta del contribuyente, por lo que este impuesto de fuente agropecuaria no variaba en función de la intensidad de explotación, sino del tamaño de la misma y del producto potencial (Ministerio de Economía y Secretaría de Estado de Agricultura, 1974, pp. 72-74).

Con la utilización de esta estrategia se esperaba conseguir los objetivos planteados, a saber: el acrecentamiento en la producción, en tanto el productor se verá estimulado a incrementar su producto para reducir el efecto del gravamen por unidad producida; la profundización de la eficiencia en el uso de los factores productivos, en función de que el incremento de producción debía lograrse no a través de la incorporación de tierras, sino fundamentalmente de mano de obra, maquinarias e introducción de nuevas tecnologías, y la reducción de la evasión y del uso indiscriminado de las desgravaciones en la promoción económica del sector. Otra consecuencia importante que se esperaba de la aplicación del impuesto a la renta potencial era la disminución del precio de la tierra, que tendería a reflejar cada vez más el valor de su productividad, en lugar de su valor especulativo.

El gobierno contaría con un instrumento jurídico específico para la puesta en práctica de los anteriores propósitos: la Ley Agraria, que reuniría en forma articulada los principios doctrinarios y las normas que hacen a los sistemas de tenencia, uso y conservación de la tierra. Los instrumentos básicos de la política estatal en materia de tierras mantuvieron su coherencia: el régimen impositivo sobre la tierra y explotaciones agropecuarias, el crédito, las normas sobre la subdivisión de la tierra, los programas de colonización y reconversión agropecuaria, y el nuevo régimen de arrendamientos.

La Ley Agraria dedicaría también especial atención a la colonización, como política fundamental en el proceso de subdivisión de tierra y expansión de la frontera agropecuaria. Este proceso abarcaría tanto a las tierras

${ }^{24}$ Diario de sesiones de la Cámara de Diputados, 3a. Reunión del 6 de junio de 1973, t. I; 6 a. Reunión del 29 de junio de 1973, t. I; 21a. Reunión del 6 de agosto de 1973, t. III, y 31a. Reunión del 11 de septiembre de 1973, t. IV. 
fiscales como a aquellas de propiedad privada que se declaren afectadas en función de ser retenidas en forma improductiva o deficientemente explotadas.

A fin de 1973 se presentó el Plan Trienal para la Reconstrucción y la Liberación Nacional 1974-1977 que propuso líneas de acción significativas, tanto en el ámbito económico y social como en el político institucional. $\mathrm{Y}$ a mediados del año siguiente se dio a conocer el anteproyecto de Ley Agraria elaborado por la Secretaría de Estado de Agricultura y Ganadería de la Nación. A partir de esta instancia estallaron las tensiones y conflictos, tanto entre los sectores rurales y el gobierno -focalizado en el equipo de la Secretaría de Agricultura-, como en el interior de esa alianza policlasista que era el peronismo gobernante.

El conocimiento del proyecto de Ley Agraria coincidió con la muerte de Perón, principal límite continente de aquella alianza; las posiciones contra el anteproyecto se constituyeron en una instancia más de confrontación entre los distintos sectores del peronismo, ávidos por ocupar el poder vacante. ${ }^{25}$

El anteproyecto propuesto no solamente servía para poner en producción toda la tierra apta para la explotación agropecuaria, sino que permitiría el acceso a la propiedad de la misma a los auténticos productores agrarios, desterrando de una vez y para siempre tanto al latifundio como al minifundio, premisa sobre la que se venía insistiendo regularmente. ${ }^{26}$

El Estado tendría un papel predominante en todo este proceso, no como un nuevo latifundista, ya que su actividad fundamental habría de ser la de un administrador, recibiendo la tierra ociosa o mal trabajada y distribuyéndola entre quienes la merezcan para que ellos -mediante la ayuda técnica y financiera necesarias- la hagan producir en todo su potencial $(\mathrm{Gi}-$ berti, agosto de 1974, p. 9), garantizando la eficiencia y la productividad.

${ }^{25}$ La Ley Agraria proponía la expropiación de la tierra improductiva, definiéndola como aquella que no hubiese estado en producción durante los últimos diez años, o hubiera producido menos que 30\% de su rendimiento normal estimado. El precio sería fijado de acuerdo con la productividad anterior, y pagado en bonos especiales del gobierno. Se facultaba al Consejo Agrario Nacional para llevar adelante expropiaciones; y establecía la posibilidad de organizar grandes unidades, con participación empresarial por parte de los trabajadores; si bien ello nunca llegó a aplicarse, acentuó el ya marcado antagonismo de todo el sector agropecuario (Di Tella, 1983, p. 57).

${ }^{26}$ Suplemento, 1974, t. IX, p. 4863. Es de destacar que el anteproyecto de Ley Agraria fue enviado por la Secretaría de Agricultura a la Comisión Nacional de Política Concertada a fines de mayo de 1974. Luego del estudio de todos los dictámenes y opiniones, la secretaría redacta la versión definitiva que fue elevada por el Ministerio de Economía a la presidencia de la nación en septiembre de 1974, solicitando su tratamiento en sesiones extraordinarias del Congreso. Esto no sucedió. Es entonces cuando un sector del bloque de diputados del Partido Intransigente -Vicente Musacchio, Rafael Marino, Tomás Arana, Héctor Portero y Mariano Lorences- lo presentan como suyo a la Cámara de Diputados, respetando su redacción original, sin que esta finalmente lo tratara. 


\section{Conclusiones}

El proceso de la redistribución de la tierra en Argentina no pudo percibir en su formulación otros procesos más o menos simultáneos y/o pretéritos que derivaron en reformas agrarias. La realidad era disímil. Aquí la producción agraria no era de subsistencia como en otros países latinoamericanos sino que se producía fundamentalmente para el mercado; el régimen agrario se basaba en general sobre el latifundio y el ausentismo, y el país no se caracterizó por contener a una densa población rural. Han incidido también la histórica preponderancia económica, social y aun simbólica de una región pampeana excedentaria en alimentos, con una estructura social de menor polarización relativa, sin presión campesina y una producción extensiva con tecnología moderna, tempranamente articulada al mercado mundial. Y respecto a las economías regionales, especialmente el Noroeste, el Noreste y Cuyo, con mayores similitudes a las realidades de la mayoría de los países latinoamericanos, fueron relegadas en el ámbito nacional, en función del menor peso para la economía en su conjunto, asentada en el eje pampeano (Lattuada, Márquez y Neme, 2012, pp. 103-105). La estructura latifundista adoptó durante el periodo en estudio, ciertas formas de modernización tecnológica y empresaria, pero acentuando la cohesión de la clase terrateniente y su poder, preservando los métodos tradicionales de distribución del ingreso rural. ${ }^{27}$

A partir del golpe militar de 1955 los sectores económicos internos desplazados del poder por el peronismo; aquellos que se habían constituido antes con el país oligárquico y liberal, se encontraban ahora en una situación de inserción dependiente en el ámbito de la expansión capitalista de posguerra.

Era necesario, entonces, modernizar la economía y la sociedad argentina, pero conviviendo en medio de condiciones conflictivas: una importante inestabilidad institucional protagonizada por la alternancia de gobiernos militares y civiles y cívico-militares, que mostró no sólo el fracaso de los militares a la hora de recomponer y controlar a la sociedad a partir de sus ideas corporativistas autoritarias, sino también el precario sistema de partidos políticos que fue incapaz de articular los intereses de las clases medias productivas de la antigua UCR y más tarde de la UCRI, manteniendo conexiones fuertes con la burguesía industrial, comercial y financiera, además de los grupos agroexportadores tradicionalmente conservadores; políticas estabilizadoras sugeridas por organismos económicos internacionales; pre-

\footnotetext{
${ }^{27}$ Un proceso similar se generó en Uruguay y por condicionantes semejantes al caso argentino: la gran propiedad en este país es relativamente productiva y la presión demográfica sobre la tierra es limitada.
} 
siones inflacionarias crónicas; penetración de empresas transnacionales; un importante proceso de concentración y centralización del capital, y nuevas funciones del Estado, tanto económicas como represivas.

En todos los casos se intentó institucionalizar estos procesos de reforma desde el Estado, por lo que se advierten algunas diferencias respecto al qué, al cómo y al para qué, lo que dependió del proyecto político correspondiente, en función de los requerimientos más inmediatos.

Si bien es a partir de la década de 1960 cuando se replicaron con más frecuencia tentativas de reforma agraria, no constituyeron en el país una novedad. El primer peronismo, a partir de la formulación de su proyecto económico, se refirió a la necesidad de generar una reforma agraria tranquila, en aras de lograr el "bienestar común [...] en un ambiente de armonía y concordia” (Lázzaro, 2015, pp. 257-259).

Desde fines de la década de 1950 y durante toda la de 1960, la ideología liberal y el desarrollismo enmarcaron la posición del país en el ámbito nacional e internacional. $\mathrm{Y}$ es precisamente durante este periodo cuando la propuesta de la reforma agraria cobró más relieve. La estructura latifundista adoptó ciertas formas de modernización tecnológica y empresaria, pero acentuando la cohesión de los sectores terratenientes, consolidando su poder, incrementando su control sobre los mecanismos institucionales, tratando de preservar los métodos tradicionales de distribución del ingreso rural (García, 1972).

Es así que se propusieron y generaron planes de transformación agraria, de promoción, de desarrollo rural tecnocrático, con énfasis en la modernización y la eficiencia, pero abiertamente distanciados de propósitos redistribucionistas, tal como lo enunciaban desde los discursos respectivos.

El peronismo que retornó en 1973 intenta reavivar en parte el proyecto primigenio de los cuarenta, pero en un marco mucho más convulsionado internamente y en el contexto internacional. Regresa la idea en torno a dar la tierra a quien la trabaja, tratando de reeditar la política social del periodo anterior con muy escasas posibilidades de concreción. Sin embargo, en la práctica se reanudaron propuesta en torno a estrategias que se articulan con incremento de productividad, eficiencia, asistencia tecnológica, etc., quedando aislado nuevamente el fundamental tema de la distribución equitativa de la tierra, pero recurriendo también discursivamente a la tan mentada reforma agraria.

Es por ello que nos interesa mostrar un juego de relaciones entre lo que se propone desde el punto de vista de la ideología de estos diferentes regímenes políticos y el pragmatismo al que acuden con el propósito de responder a condicionamientos medianamente coyunturales, probando que desde distintas posiciones políticas terminan proponiendo y/o ejecutando los mismos procedimientos. Y en la práctica coinciden, con algunas 
variaciones en las estrategias, en plantear métodos de acción sin considerar los medios empleados, siendo el principio reconocido el de la eficiencia del fin o del éxito.

En efecto, el peronismo de la década de 1940 profundiza el proceso de acumulación de capital industrial por sustitución de importaciones que había comenzado en la década de 1930 y se profundizó durante el periodo de guerra y posguerra. A partir de 1955, y con algunas variantes, la estrategia de acumulación se orienta hacia el reordenamiento del sistema internacional, basado en la integración y dependencia del sistema capitalista, en cuyo marco la burguesía agraria mantenía una primordial función en tanto proveedora de divisas. En 1966 y hasta 1973, la estrategia de acumulación estaba ya instalada en la fracción de la burguesía ligada al capital extranjero, con el protagonismo de la tecnocracia. El peronismo intentó alterar este proceso de acumulación a favor de un proyecto de capitalismo nacional autónomo, pero las condiciones no lo permitieron.

En síntesis, en el contexto de estas diferenciaciones, la propuesta de reforma agraria estuvo presente sistemáticamente, con objetivos explícitos y maniobras instrumentales divergentes respecto a su enunciación. No obstante, sobre la base de una constante -aferrados a la retórica en torno a la reforma agraria-, la intención de la distribución equitativa de la tierra fue la gran ausente, enmascarada con proyectos que tendieron a un propósito opuesto, la mayor concentración. ${ }^{28}$

\section{LISTA DE REFERENCIAS}

Acta de Compromiso del Estado y los Productores para una Política Concertada de Expansión Agropecuaria y Forestal (1973). Revista de la Bolsa de Cereales.

${ }^{28}$ En efecto, según datos del Comité Interamericano de Desarrollo Agrícola para 1965, ha quedado demostrado que ni siquiera en los países semiindustrializados de la zona templada, como es el caso de Argentina, se ha roto la "ecuación tradicional concentración latifundista/pulverización minifundista". En este país, en el que la industria manufacturera representa cerca de la tercera parte del producto bruto interno, las explotaciones de tipo latifundista representan $0.8 \%$, controlan $40 \%$ de la tierra, ocupan apenas $6 \%$ de la mano de obra agrícola y contribuyen con $15 \%$ del valor de la producción, y en el otro extremo de la escala, las unidades de tipo minifundistas constituyen $43 \%$, disponen de $3 \%$ de la tierra, soportan una carga laboral de $30 \%$ de la mano de obra y aportan casi tanto como los latifundios ( $12 \%$ de la producción). Esta imagen del campo argentino demuestra que es muy elevada la concentración de la tenencia agraria y muy bajo el nivel de eficiencia de la gran explotación latifundista, ya que con $40 \%$ de la tierra produce apenas un valor equiparable al de los sectores minifundistas que operan con 3\%. A su vez las explotaciones intermedias representan no sólo el mayor aporte en el valor de la producción agropecuaria (47\%), sino la mayor capacidad ocupacional de mano de obra agrícola (39\%), y es a este proceso social al que debe atribuirse que las políticas populistas no se hayan orientado hacia la reforma agraria, sino tan sólo hacia la regulación de rentas y aparcerías (CIDA, 1966). 
Am. Lat. Hist. Econ., año 24, núm. 3, septiembre-diciembre, 2017, pp. 193-223

Alizón, J. (1956). El estado económico del país y las medidas adoptadas para lograr su restablecimiento. Córdoba: s. e.

BALSA, J. (1988). El desvanecimiento del mundo chacarero. Transformaciones sociales en la agricultura bonaerense 1937-1988. Buenos Aires: Universidad Nacional de Quilmes.

BARsky, O. (1993). La evolución de las políticas agrarias en Argentina. En AA.VV. La problemática agraria. Nuevas aproximaciones (pp. 51-88). Buenos Aires: Centro Editor de América Latina.

Blanco, M. (2007). Reforma en el agro pampeano. Arrendamiento, propiedad y legislación agraria en la provincia de Buenos Aires 1940-1960. Buenos Aires: Universidad Nacional de Quilmes.

BRETON, V. (1994). ¿La tierra para quien la trabaja? Reforma agraria, desarrollo rural y crisis del campesinado en América Latina (1950-1990) (Quaderns del Departamento de Geografia i Historia). México: Universitat de Leida, Espai/Temps.

Chonchol, J. (2003). La reforma agraria en América Latina. En J. CHOnchol, Proceso agrario en Bolivia y América Latina (pp. 205-222). La Paz: Universidad Mayor de San Andrés/Plural Editores.

Comisión Interamericana de Desarrollo Agrícola [Cida] (1966). Tenencia de la tierra y desarrollo socioeconómico del sector agrícola. Informe regional. Washington: Unión Panamericana.

Di Tella, G. (1983). Perón-Perón, 1973-1976. Buenos Aires: Hyspamérica.

El impuesto como impulsor de la actividad agropecuaria (1984). Revista Realidad Económica, 59, 46-47.

El pensamiento del gobierno a través de la palabra del Ministro de Finanzas (1955). Revista La Res, 23.

Flichman, G. (1978). Notas sobre el desarrollo agropecuario en la región pampeana (O por qué Pergamino no es Iowa). Estudios CEDES, 1(4-5).

FORNI, F. y TORT, M. I. (1984). Las explotaciones familiares en la producción de cereales de la región pampeana argentina. Buenos Aires: Centro de Estudios e Investigaciones Laborales.

FrondizI, A. (1965). El problema agrario argentino. Buenos Aires: Desarrollo.

Funes, V. (1967). El impuesto a la renta potencial de la tierra. En Sociedad Rural Argentina, Anales de la Sociedad Rural Argentina. Argentina: Sociedad Rural Argentina.

FurTado, C. (1966). Desarrollo y estancamiento en América Latina (Enfoque estructuralista). Desarrollo Económico, 6(22-23), 191-225. DoI: 10.2307/3465725

García, A. (1972). Atraso y dependencia en América Latina. Hacia una teoría latinoamericana del desarrollo. Buenos Aires: El Ateneo.

García, A. (1973). Sociología de la reforma agraria en América Latina. Buenos Aires: Amorrortu.

Giberti, H. (agosto, 1974). La Ley Agraria. Opina Horacio Giberti. El Campo en Marcha.

Gras, C. y Hernández, V. (2016). Radiografía del nuevo campo argentino. Del terrateniente al empresario transnacional. Buenos Aires: Siglo XXI. 
GROPPO, P. (1977). La FAO y la reforma agraria en América Latina: hacia una nueva visión. Santiago: Desarrollo Rural-FAO.

HARY, P. (1961). ¿Reforma agraria o promoción rural? Buenos Aires: Rural.

Ibarbia, D. (1956). Plan de transformación agraria. Presentado por el ingeniero agrónomo Diego Ibarbia (Mimeo.). Cámara Central de Arrendamientos, Argentina.

JORDÁN, F. (1989). La economía campesina: crisis, reactivación y desarrollo. San José de Costa Rica: Instituto Interamericano de Cooperación para la Agricultura.

Kossacoff, B. y AzPIAZu, D. (1989). La industria argentina: desarrollo y cambios estructurales. Buenos Aires: Consejo Empresarial de América Latina/Comisión Económica para América Latina.

Lattuada, M. (1986). La política agraria peronista (1943-1983). Buenos Aires: Consejo Empresarial de América Latina.

Lattuada, M., Márquez, S., y Neme, J. (2012). Desarrollo rural y política. Reflexiones sobre la experiencia argentina desde uma perspectiva de gestión. Buenos Aires: Centro de Integración, Comunicación, Cultura y Salud.

LÁzzAro, S. (2005). La política agraria de la autodenominada Revolución Argentina. En G. Galafassi, El campo diverso. Enfoques y perspectivas de la Argentina agraria del siglo XX. Buenos Aires: Universidad Nacional de Quilmes.

LÁzZARO, S. (2013a). Acuerdos y confrontaciones: la política agraria peronista en el marco del Pacto Social. Historia Crítica, 51, 145-168.

LÁZZARO, S. (2013b). Inequidad rural, desarrollismo y políticas de reforma agraria: el caso de la provincia de Buenos Aires en la década de 1950. Revista de Historia Americana y Argentina, 48(2), 156-192.

LÁzZARO, S. (2015). La política agraria del peronismo. El acceso a la propiedad de la tierra: arrendamientos y colonización. En O. Graciano y G. Olivera, Agro y política en Argentina, t. II: Actores sociales, partidos políticos e intervención estatal durante el peronismo 1943-1955. Buenos Aires: Centro de Integración, Comunicación, Cultura y Salud.

Liga Argentina para Promover la Recuperación Económica (LAPREN) (1959). El problema de la reforma agraria (Folleto). Buenos Aires.

MARTínez DE HOZ, J. (1965). La reforma agraria y la explotación agropecuaria en la región pampeana argentina (Mimeo.). Argentina.

Mascali, H. (1986). Desocupación y conflictos laborales en el campo argentino (1940-1960). Buenos Aires: Centro Editor de América Latina.

Ministerio de Economía y Secretaría de Estado de Agricultura y Ganadería DE LA NACIÓN (1974). Plan sectorial agropecuario 1974-1977 (t. I, versión preliminar) (Mimeo). Buenos Aires.

NiCANOFF, S. y PitA, F. (2006). Regreso y fracaso en tres actos: el peronismo 1973-1976. En AA. VV., Pasados presentes (pp. 319-351). Buenos Aires: Dialektik.

O’Donnell, G. (1982). 1966-1973. El Estado burocrático autoritario. Buenos Aires: De Belgrano. 
ORTEga, E. (1990). De la reforma agraria a las empresas asociativas. Revista de la CEPAL, 40, 105-122.

OszlaK, O. (2016). La trama oculta del poder. Reforma agraria y comportamiento político de los terratenientes chilenos, 1958-1973. Santiago de Chile: LOM Ediciones/Universidad de Santiago de Chile.

PAZ, P. (1985). Proceso de acumulación y política económica. En AA. VV., Crisis de la dictadura argentina. Política económica y cambio social (1976-1983) (pp. 13-106). Buenos Aires: Siglo XXI.

Presidencia De la Nación (1975). Reseña general de actividades desde el 25 de mayo de 1973. Buenos Aires.

Quiroga, H. (1985). Estado, crisis económica y poder militar (1880-1981). Buenos Aires: Consejo Empresarial de América Latina.

Reboratti, C. (1985). Reforma agraria en la Argentina: entre la utopía y la indiferencia. En II Encuentro de Geógrafos de América Latina, República Oriental del Uruguay. Recuperado de: http://www.observatoriogoegraficoamericalatina.org.mx

San Esteban, R. (1980). El agro argentino. Crisis de estructura. Buenos Aires: Quipo.

SidicARO, R. (2002). Los tres peronismos. Estado y poder económico 1946-1955/19731976/1989-1999. Buenos Aires: Siglo XXI.

SLUTZKY, D. (1968). Aspectos sociales del desarrollo rural en la pampa húmeda argentina. Desarrollo Económico, 8(29), pp. 95-135. DOI: 10.2307/3465915

Sociedad Rural Argentina (SRA) (1957-1966). Anales de la Sociedad Rural Argentina. Argentina: Autor.

Sociedad Rural Argentina (SRA) (1966). La tierra y la producción agraria en la Argentina. Panorama de su evolución histórica y realidad actual. Buenos Aires: Autor.

Transcripción de un informe radial del presidente provisional sobre el campo y la realidad económica (1955). Mundo Agrario. Revista Mensual de Ganadería, Agricultura e Industria, 8 .

\section{Hemerografía}

Anales de la Sociedad Rural Argentina, Buenos Aires, Argentina.

Diario de sesiones de la Cámara de Diputados, Congreso Nacional, Argentina.

Diario de sesiones de la Cámara de Senadores, Congreso Nacional, Argentina.

Mundo Agrario. Revista Mensual de Ganadería, Agricultura e Industria, Buenos Aires, Argentina.

Primera Plana, Buenos Aires, Argentina.

Revista de la Bolsa de Cereales, Buenos Aires, Argentina.

Revista El Campo en Marcha, Buenos Aires, Argentina.

Revista La Res, Buenos Aires, Argentina.

Revista Realidad Económica, Buenos Aires, Argentina.

Suplemento, Cámara de Diputados de la Nación, Congreso Nacional, Argentina. 